Supporting Information for:

\title{
Hydrogen Bonding of Ammonia with (H,OH)-Si(001) Revealed by Experimental and ab initio Photoelectron Spectroscopy
}

Lucia Pérez Ramirez ${ }^{1}$, Jean-Jacques Gallet ${ }^{1,2 *}$,Fabrice Bournel ${ }^{1,2}$, Florence Lim ${ }^{1}$, Stéphane Carniato $^{1}$, François Rochet ${ }^{1 *}$, Oleg V. Yazyev ${ }^{3}$, Alfredo Pasquarello $^{3}$, Elena Magnano ${ }^{4,5}$ and Federica Bondino 4

${ }^{1}$ Sorbonne Université, CNRS, Laboratoire de Chimie Physique matière et Rayonnement, UMR 7614, 4 place Jussieu, 75005 Paris, France

2 Synchrotron SOLEIL, L'Orme des Merisiers, Saint-Aubin - BP 4891192 Gif-surYvette CEDEX, France

${ }^{3}$ Chaire de Simulation à l'Echelle Atomique (CSEA), Ecole Polytechnique Fédérale de Lausanne (EPFL), CH-1015 Lausanne, Switzerland

${ }^{4}$ IOM-CNR, Laboratorio TASC, 34149 Basovizza, Trieste, Italy

${ }^{5}$ Department of Physics, University of Johannesburg, PO Box 524, Auckland Park 2006, South Africa 
*Corresponding authors: francois.rochet@sorbonne-universite.fr; jean-

jacques.gallet@sorbonne-universite.fr

Content: 13 pages, 5 figures and 1 table.

Si $2 p$ spectrum of $(\mathrm{H}, \mathrm{OH})-\mathrm{Si}(001), \mathrm{O} 1 \mathrm{~s}$ and $\mathrm{N} 1 \mathrm{~s}$ intensity normalization, quantum chemistry DFT O 1s ionization energies, $\mathrm{O} 1 \mathrm{~s}$ experimental spectra, trimethylamine $\mathrm{N} 1 \mathrm{~s}$ spectrum. 


\section{S1. The Si 2p spectrum of $(\mathrm{H}, \mathrm{OH})-\mathrm{Si}(001)$}

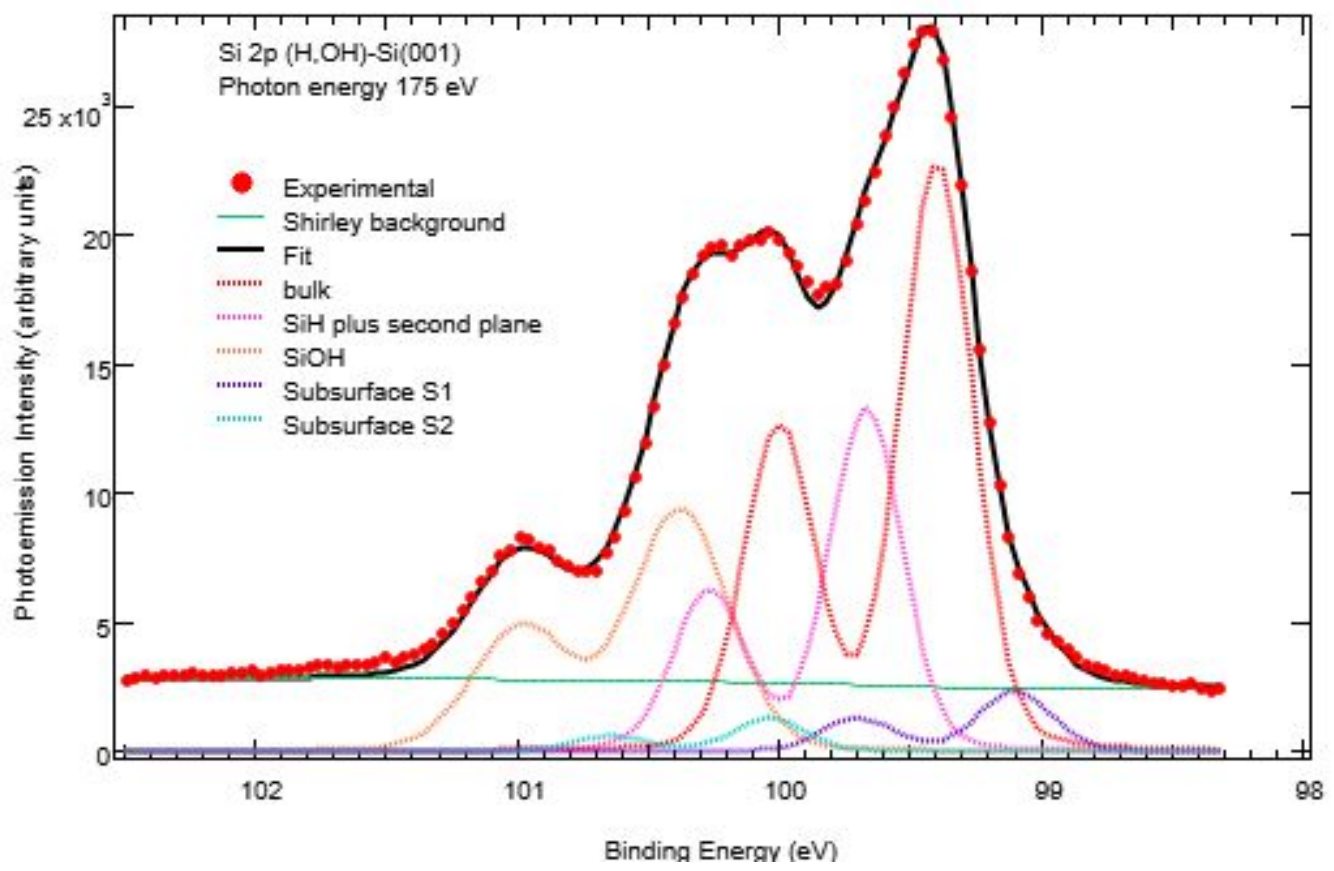

\begin{tabular}{|c|c|c|c|c|c|}
\hline Component & $\begin{array}{c}\text { Si } 2 p_{3 / 2} \\
\text { Binding Energy } \\
(\mathrm{eV})\end{array}$ & $\begin{array}{r}\text { Lorentzian } \\
\text { FWHM }(\mathrm{eV})\end{array}$ & $\begin{array}{r}\text { Gaussian } \\
\text { FWHM (eV) }\end{array}$ & $\begin{array}{l}\text { Spectral weight } \\
(\%)\end{array}$ & $\begin{array}{c}\text { Core } \\
\text { Level shifts } \\
(\mathrm{eV})\end{array}$ \\
\hline $\mathrm{Si}^{0}$ & 99.40 & 0.045 & 0.300 & 44.63 & 0 \\
\hline $\mathrm{SiH} / 2^{\text {nd }}$ plane & 99.67 & 0.045 & 0.300 & 24.60 & 0.27 \\
\hline $\mathrm{SiOH}$ & 100.38 & 0.045 & 0.414 & 23.90 & 0.98 \\
\hline S1 & 99.10 & 0.045 & 0.300 & 4.5 & -0.30 \\
\hline S2 & 100.04 & 0.045 & 0.300 & 2.4 & 0.64 \\
\hline
\end{tabular}

Figure S1. Si $2 p$ spectrum of the (H,OH)-Si(001) surface at $300 \mathrm{~K}$. The table below the spectrum collects the binding energy positions ( $\mathrm{eV})$, the Lorentzian and Gaussian full widths at half maximum (FWHM) and the spectral weights of each component. 
The Si $2 p$ core level of the $(\mathrm{H}, \mathrm{OH})-\mathrm{Si}(001)$ surface (shown in Figure $\mathrm{S} 1$ ) is measured at $h_{V}=$ $175 \mathrm{eV}$. At a kinetic energy of $\sim 75 \mathrm{eV}$, the inelastic mean free path $\lambda$ is $\sim 4.8 \mathrm{~nm} .{ }^{1}$ Considering the exit angle of the photoelectrons with respect to the surface normal $\left(60^{\circ}\right)$, the effective escape depth $\lambda \cos \left(60^{\circ}\right)$ is small $\sim 2.4 \AA$, which ensures a good surface sensitivity (a surface plane is worth $46 \%$ of the spectral weight). The spectrum is very similar to those shown in our previous publications. $^{2,3}$ It is fitted with five doublets (the spin-orbit splitting is $0.602 \mathrm{eV}$ and the $2 p_{1 / 2}: 2 p_{3 / 2}$ branching ratio is 0.5$)$. We use true Voigt functions with a Lorentzian FWHM of $0.045 \mathrm{eV}$. Gaussian widths are indicated in the table. We find the Si $2 \mathrm{p}_{3 / 2}$ component of bulk silicon $\mathrm{Si}^{0}$ component at $99.40 \mathrm{eV}$. The " $\mathrm{SiH}$ plus $2^{\text {nd }}$ plane" component is at $+0.27 \mathrm{eV}$ from $\mathrm{Si}^{0}$, the $\mathrm{SiOH}\left(\mathrm{Si}^{1+}\right)$ component at $+0.98 \mathrm{eV}$. As the $\mathrm{SiOH}$ coverage is $0.5 \mathrm{ML}, 48 \%$ of the spectral weight corresponds to the surface plane, which shows the high surface sensitivity. Note the absence of the $\mathrm{Si}^{2+}$ oxidation state at about $+1.8 \mathrm{eV}$ from $\mathrm{Si}^{0}$ (and of higher oxidation states). This proves the absence of subsurface oxidation. Only OHs are present on the surface. Two more small subsurface components are needed to obtain a good fit. The "S1" component at $-0.30 \mathrm{eV}$, distinct from that of the "up" dimer atom component of the clean surface that appears at $-0.57 \mathrm{eV}, 3,4$ and the "S2" component at $+0.64 \mathrm{eV}$.

\section{S2. O 1s and N 1s normalization with respect to Si LVV}

Figure $\mathrm{S} 2$ presents the $\mathrm{N} 1$ s spectra of a $\mathrm{Si}(001)-2 \times 1$ surface after saturation with $\mathrm{NH}_{3}$ at a pressure of $5 \times 10^{-9} \mathrm{mbar}$ (blue), and a silicon surface after 10 minutes of water dosing $\left(\mathrm{P}=5 \times 10^{-9}\right.$ mbar) plus approximately 20 minutes of ammonia dosing $\left(\mathrm{P}=5 \times 10^{-9} \mathrm{mbar}\right)$ (red). The spectra are normalized using the Si LVV Auger edge to evaluate the variation of ammonia quantities on the surface. The area under the $\mathrm{N} 1 \mathrm{~s}$ peak of the blue curve, measured from the $\left(\mathrm{H}, \mathrm{NH}_{2}\right)-$ $\mathrm{Si}(001)$ surface, ${ }^{5}$ corresponds exactly to $0.5 \mathrm{ML}$. Taking this as a standard, we find that the 
calculated area under the N 1s peak of the red curve is $0.40 \mathrm{ML}$. Since the red spectrum is taken just after the end of the ammonia dosing process given in Figure 4 of the article, we deduce from the normalized $\mathrm{N} 1 \mathrm{~s}$ intensity the nitrogen coverages as a function of time for the different species.

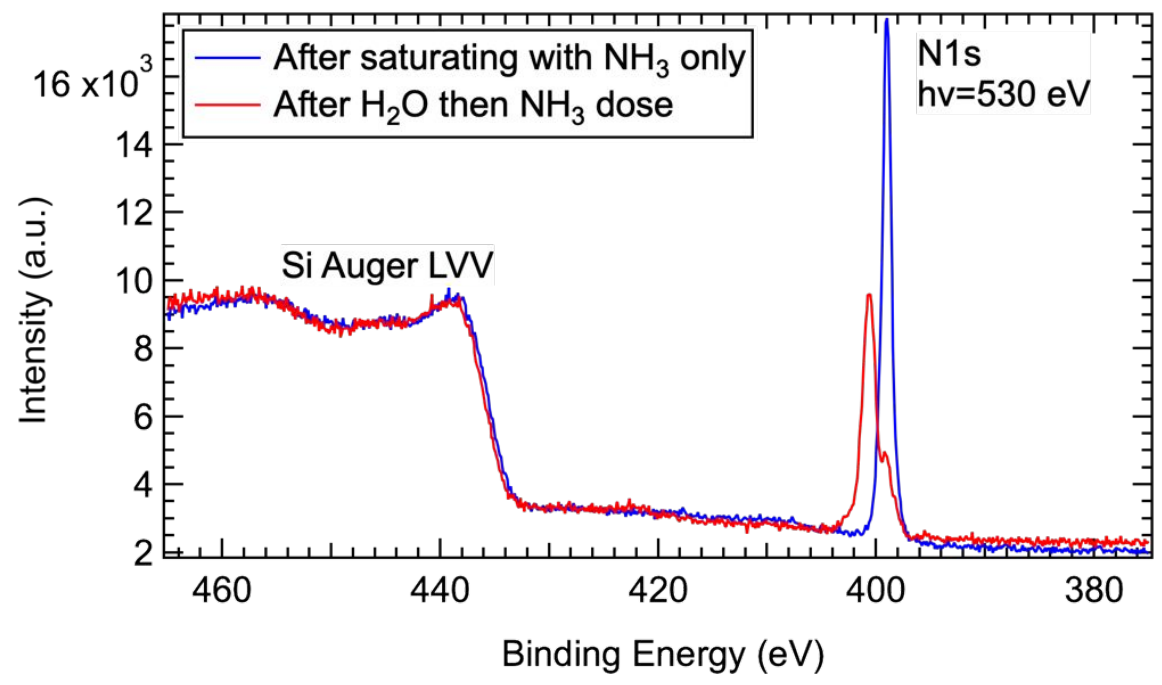

Figure S2. Si Auger LVV and N 1 s core level peak recorded at hv $=530 \mathrm{eV}$ from the $\mathrm{NH}_{3^{-}}$ covered silicon surface and the $\mathrm{NH}_{3}-(\mathrm{H}, \mathrm{OH})$-covered surface.

Figure $\mathrm{S} 3$ shows the $\mathrm{O}$ 1s spectra of the silicon surface after 10 minutes of water dosing at room temperature $\left(\mathrm{P}=5 \times 10^{-9}\right)$ (blue), after cooling down to $130 \mathrm{~K}$ (red), and, finally, after 20 minutes of $\mathrm{NH}_{3}$ dosing at $\mathrm{P}=5 \times 10^{-9}$ (green) at $130 \mathrm{~K}$. Given that the dissociation of water on the silicon dimers at room temperature leads to the formation of half a monolayer (ML) of $\mathrm{SiH}$ and half a monolayer of $\mathrm{SiOH}$, the area under the $\mathrm{O} 1 \mathrm{~s}$ peak of the blue curve correspond to 0.5 ML of $\mathrm{OH}$ species exactly. The $(\mathrm{H}, \mathrm{OH})-\mathrm{Si}(001)$ surface formed at $300 \mathrm{~K}$ serves as standard to estimate the oxygen coverages. Therefore, the calculated oxygen coverage after cooling down in $\mathrm{UHV}$ is $0.57 \mathrm{ML}$, and after ammonia dosing is $0.50 \mathrm{ML}$. 
Both for $\mathrm{N}$ and $\mathrm{O}$ coverages, the relative uncertainty due to adjusting the $\mathrm{Si} \mathrm{LVV}$ edges is about $5 \%$ and that due to measuring the spectral intensity is $3 \%$. The overall error in measuring is estimated to be $\sim 8 \%$.

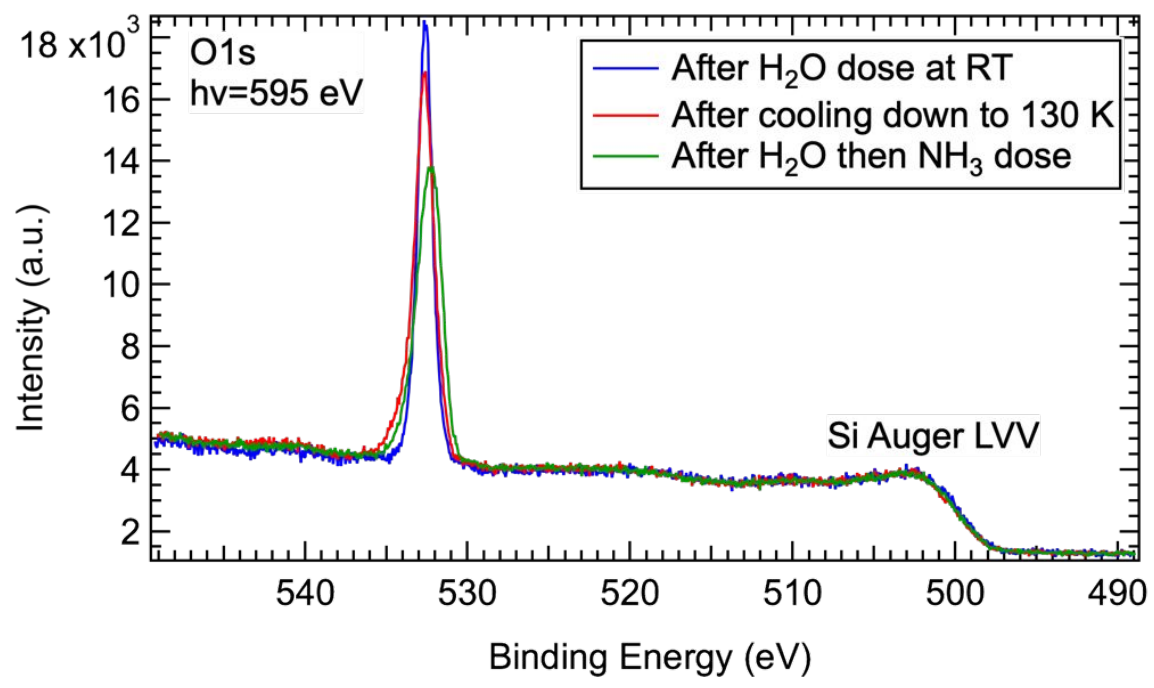

Figure S3. Si Auger LVV and O 1 s core level peak recorded at $h v=595 \mathrm{eV}$ from the silicon surface after water saturation at room temperature (blue), then cooling down to $130 \mathrm{~K}$ (red), and after NH3 dosing under a pressure of $5 \times 10^{-9}$ mbar (green).

\section{S3. Cluster QC DFT O 1s Ionization energies ( IE $\left._{Q C}^{\text {th }}\right)$}

\section{Single dimer clusters}

The results of the O 1s cluster QC DFT calculations obtained for single-dimer clusters, $\mathrm{Si}_{9} \mathrm{H}_{12}(\mathrm{OH}, \mathrm{H})($ single $\mathrm{OH})$ and $\mathrm{Si}_{9} \mathrm{H}_{12}(2 \mathrm{OH})$ (ODIM OH pairs), are collected in Table $\mathrm{S} 1$ for various configurations. Calculations of $\mathrm{O} 1 \mathrm{~s}$ ionization energies $\mathrm{IE}_{Q C}^{\mathrm{th}}$ were limited to this small cluster. While such an approach obviously cannot represent the variety of configurations encountered on the real surface, trends can be highlighted that are useful for interpreting the experimental spectra. 
The $\mathrm{IE}_{Q C}^{\text {th }}$ of isolated the isolated hydroxyl is found at $537.86 \mathrm{eV}$. It is used as an energy reference to calculate $\Delta \mathrm{IE}_{Q C}^{\text {th }}$ of other configurations.

\begin{tabular}{|c|c|c|c|c|}
\hline Configuration & Cluster & H-bond length $(\AA)$ & O1s IE $E_{Q C}^{\text {th }}(\mathrm{eV})$ & $\begin{array}{l}\Delta \mathrm{IE}_{Q C}^{t h} \\
(\mathrm{eV})\end{array}$ \\
\hline Free $\mathrm{H}_{2} \mathrm{O}$ & NA & NA & 539.78 & 1.92 \\
\hline Single $\mathrm{OH}$ & $\mathrm{Si}_{9} \mathrm{H}_{12}(\mathrm{H}, \mathrm{OH})$ & NA & 537.86 & 0 \\
\hline Single $\mathrm{OH}(\mathrm{D}) \ldots \mathrm{NH}_{3}(\mathrm{~A})$ & $\mathrm{Si}_{9} \mathrm{H}_{12}\left(\mathrm{H}, \mathrm{OH}, \mathrm{NH}_{3}\right)$ & $\mathrm{O}-\mathrm{H} \ldots \mathrm{NH}_{3} \quad 1.84$ & 536.55 & -1.31 \\
\hline Single $\mathrm{OH}(\mathrm{a}) \ldots \mathrm{NH}_{3}(\mathrm{~d})$ & $\mathrm{Si}_{9} \mathrm{H}_{12}\left(\mathrm{H}, \mathrm{OH}, \mathrm{NH}_{3}\right)$ & $\mathrm{H}-\mathrm{O} \ldots \mathrm{H}-\mathrm{NH}_{2} 2.17$ & 537.84 & -0.02 \\
\hline $\begin{array}{l}\text { ODIM pair } \mathrm{OH}(\mathrm{D}) \ldots \mathrm{OH}(\mathrm{A}) \\
\text { ODIM pair } \mathrm{OH}(\mathrm{D}) \ldots \mathrm{OH}(\mathrm{A})\end{array}$ & $\mathrm{Si}_{9} \mathrm{H}_{12}(2 \mathrm{OH})$ & O-H...O-H 1.64 & $\begin{array}{l}536.28 \\
538.20\end{array}$ & $\begin{array}{l}-1.58 \\
0.34\end{array}$ \\
\hline $\begin{array}{l}\text { ODIM OH(D) ... } \mathrm{NH}_{3}(\mathrm{~A}, \mathrm{~d}) \ldots \mathrm{OH}(\mathrm{A}) \\
\mathrm{ODIM} \mathrm{OH}(\mathrm{D}) \ldots \mathrm{NH}_{3}(\mathrm{~A}, \mathrm{~d}) \ldots \mathrm{OH}(\mathrm{A})\end{array}$ & $\mathrm{Si}_{9} \mathrm{H}_{12}\left(2 \mathrm{OH}, \mathrm{NH}_{3}\right)$ & $\begin{array}{c}\mathrm{O}-\mathrm{H} . . . \mathrm{NH}_{3} 1.77 \\
\mathrm{H}_{2} \mathrm{NH} \ldots . . \mathrm{O}-\mathrm{H} 2.10\end{array}$ & $\begin{array}{l}536.50 \\
538.00\end{array}$ & $\begin{array}{l}-1.36 \\
0.14\end{array}$ \\
\hline 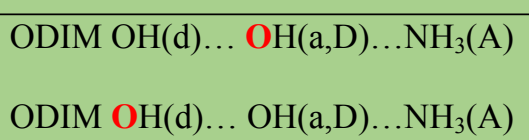 & $\mathrm{Si}_{9} \mathrm{H}_{12}\left(2 \mathrm{OH}, \mathrm{NH}_{3}\right)$ & $\begin{array}{l}\mathrm{O}-\mathrm{H} . . . . \mathrm{NH}_{3} 1.84 \\
\text { O-H...OH } 2.64\end{array}$ & $\begin{array}{l}536.84 \\
537.36\end{array}$ & $\begin{array}{l}-1.02 \\
-0.5\end{array}$ \\
\hline
\end{tabular}

Table S1. Theoretical O 1s ionization potential energies $\mathrm{IE}_{Q C}^{\text {th }}$ calculated via a DFT QC silicon cluster approach $\left(\mathrm{Si}_{9} \mathrm{H}_{12}\right.$, the "one-bare-dimer" cluster). $\Delta I E_{Q C}^{\text {th }}$ values are referenced to the $I E_{Q C}^{\text {th }}$ of the isolated $\mathrm{OH}(537.86 \mathrm{eV})$. (...) denotes a $\mathrm{H}$-bond. $\mathrm{OH}$ and $\mathrm{NH}_{3}$ can donate $(\mathrm{D}$ or d) or accept ( $A$ or a) H atoms. A capital letter corresponds to a strong $H$ bond, a lower case to a weak $H$ bond (the "proxy" of the H bond strength is its length given in the table).

Pairs of $\mathrm{OH}$ sitting on the same dimer establish strong $\mathrm{H}$ bonds. Indeed, the optimized $\mathrm{O}-\mathrm{O}$ distance is $2.60 \AA$ (the Si-Si dimer bond length is $2.35 \AA$ ). The short H-O...H-O H-bond length $(1.64 \AA)$ means that the effect on $\mathrm{O} 1 \mathrm{~s} \mathrm{IE}_{Q C}^{\text {th }}$ is large. The $\mathrm{IE}_{Q C}^{\text {th }}$ the $\mathrm{OH}(\mathrm{A})$ and $\mathrm{OH}(\mathrm{D})$ species are $538.20 \mathrm{eV}$ and $536.28 \mathrm{eV}$, respectively. This corresponds to an energy splitting of $1.92 \mathrm{eV}$ : the acceptor shifts by $\Delta \mathrm{IE}_{Q C}^{t h}=+0.34 \mathrm{eV}$ and the donor by $\Delta \mathrm{IE}_{Q C}^{t h}=-1.58 \mathrm{eV}$, with respect to the isolated $\mathrm{OH}$ case (Table S1). This situation is reminiscent of that of the $\left(\mathrm{H}_{2} \mathrm{O}\right)_{2}$ dimer, see Carniato et al. ${ }^{6}$ and Table 1 , where the acceptor moves by $+0.56 \mathrm{eV}$ and the donor by 1.17 $\mathrm{eV}$ with respect to the case of the isolated water molecule. The same trend in sign for the core 
level shifts and a larger shift magnitude for the donor than for the acceptor were also calculated by Garcia-Gil and coworkers in the case intermolecular H-bond in organic molecules. ${ }^{7}$

$$
\text { Adsorption on } \mathrm{Si}_{9} \mathrm{H}_{12}(\mathrm{H}, \mathrm{OH})
$$

The ammonia molecule can be attached to the single $\mathrm{OH}$ of the $\mathrm{Si}_{9} \mathrm{H}_{12}(\mathrm{OH}, \mathrm{H})$ cluster. In the $\mathrm{OH}(\mathrm{D}) \ldots \mathrm{NH}_{3}(\mathrm{~A})$ configurations the H-bond length is $1.84 \AA$, and $\Delta \mathrm{IE}_{Q C}^{\text {th }}=-1.31 \mathrm{eV}$. A minimum energy configuration can also be achieved by presenting one hydrogen of the molecule in front of the oxygen of the hydroxyl. The hydrogen bond is then weak $\left(\mathrm{HO}(\mathrm{a}) \ldots \mathrm{HNH}_{2}(\mathrm{~d})\right.$ is $2.17 \AA$ long$)$ and $\Delta \mathrm{IE}_{Q C}^{\text {th }}$ is zero.

\section{Adsorption on $\mathrm{Si}_{9} \mathrm{H}_{12}(2 \mathrm{OH})$}

We then investigated the adsorption of an ammonia molecule on $\mathrm{Si}_{9} \mathrm{H}_{12}(2 \mathrm{OH})$. Ammonia can be inserted between the two hydroxides, to make a $\mathrm{OH}(\mathrm{D}) \ldots \mathrm{NH}_{3}(\mathrm{~A}, \mathrm{D}) \ldots \mathrm{OH}(\mathrm{A})$ configuration. The "D" and "A" H-bond lengths are 1.77 and $2.10 \AA$. The $\Delta \mathrm{IE}_{Q C}^{\text {th }}$ of $\mathrm{OH}(\mathrm{D})$ is worth $-1.36 \mathrm{eV}$ and that of $\mathrm{OH}(\mathrm{A})$ is $+0.14 \mathrm{eV}$. The energy shifts are again non symmetric with respect to the $\mathrm{IE}_{Q C}^{\text {th }}$ of the isolated $\mathrm{OH}$.

The ammonia molecule can also be placed in an end-on position, to make a $\mathrm{OH}(\mathrm{d}) \ldots$ $\mathrm{OH}(\mathrm{a}, \mathrm{D}) \ldots \mathrm{NH}_{3}(\mathrm{~A})$ configuration, with a "d" bond length of $2.64 \AA$ and a "D" one of $1.84 \AA$. Interestingly we have produced a $\mathrm{OH}(\mathrm{a}, \mathrm{D})$ hydroxyl making a double H-bond. The $\Delta \mathrm{IE}_{Q C}^{\text {th }}$ of $\mathrm{OH}(\mathrm{a}, \mathrm{D})$ is $=-1.02 \mathrm{eV}$, smaller in magnitude than that of $\mathrm{OH}(\mathrm{D})$ in the previous, bridge configuration. 


\section{S4. Experimental O 1s XPS spectra and their interpretation}

We present in Figure S4 the experimental O 1s spectra of the $(\mathrm{H}, \mathrm{OH})-\mathrm{Si}(001)$ surface at 300 $\mathrm{K}$, at $130 \mathrm{~K}$ under vacuum, and then exposed to ammonia. The spectrum of $(\mathrm{H}, \mathrm{OH})-\mathrm{Si}(001)$ recorded at $300 \mathrm{~K}$ (bottom curve) is fitted by a single Gaussian component positioned at a binding energy of $532.62 \mathrm{eV}$. The FWHM is $1.15 \mathrm{eV}$. H-bonds are not expected to be stabilized at this temperature. ${ }^{8}$ Therefore the line at $532.62 \mathrm{eV}$ is characteristic of "isolated" OHs.

As soon as the temperature drops to $130 \mathrm{~K}$ (middle curve), the main component remains at the same position $(532.64 \mathrm{eV})$ but broadens $(\mathrm{FWHM}=1.46 \mathrm{eV})$. The broadening may be due to stabilization of $\mathrm{H}$ bonds between hydroxyls. The effect $\mathrm{OH}$ pairing in SP patterns leads to a theoretical $\mathrm{IE}_{Q \mathrm{C}}^{\text {th }}$ splitting of $0.25 \mathrm{eV}$ between $\mathrm{OH}(\mathrm{a})$ and $\mathrm{OH}(\mathrm{d}) .{ }^{6}$ The $\mathrm{OH}$ pairing in $\mathrm{CBP}$ should lead to a still smaller splitting. The pairing of ODIM OH pairs leads to very large change in $\mathrm{IE}_{Q C}^{\text {th }}$ (see Section S3), but we see no clear reflection of it in the experimental spectrum (we recall that the effect is asymmetric as the magnitude of the donor shift is greater than that of the acceptor one). In fact, complex $\mathrm{H}$-bonded $\mathrm{OH}$ patterns are likely to form on the surface, that are difficult to take into account with cluster methods. In addition, relatively long-distance electrostatic effects between $\mathrm{OHs}$ can also complicate the picture. In addition to the main $\mathrm{OH}$ component, we need to introduce a Gaussian component at $534.30 \mathrm{eV}$. The binding energy shift is $1.70 \mathrm{eV}$ with respect to the $\mathrm{OH}$ component at $532.62 \mathrm{eV}$, and this value is close to the $\Delta \mathrm{IE}_{Q C}^{\text {th }}$ of molecular water $(1.9 \mathrm{eV}) . \mathrm{H}_{2} \mathrm{O}$ coming from the residual gas in the chamber is likely coadsorbed on the surface during cooling in UHV. The component represents $9 \%$ of the spectral weight (i.e. $\sim 0.05 \mathrm{ML}$ ). This is in good agreement with the increase in oxygen coverage to 0.57 ML.

When the $(\mathrm{H}, \mathrm{OH})-\mathrm{Si}(001)$ surface is covered by molecular ammonia at $130 \mathrm{~K}$, we observe sizeable changes in the spectrum (top curve of Figure S4). The coverage of $\mathrm{H}$ bonded ammonia 
is in the range $0.22-0.37 \mathrm{ML}$. The spectrum can always be fitted by two Gaussians, but the small peak that accounts for the asymmetry at high binding energy is now positioned at $533.7 \mathrm{eV}^{1}$. In fact, the peak attributed to $\mathrm{H}_{2} \mathrm{O}$ (at $534.3 \mathrm{eV}$ ) has disappeared. This suggests that the water molecules have been displaced by the ammonia molecules and is in line with the fact that the oxygen coverage has returned to $0.5 \mathrm{ML}$. Concerning the main component, it is strongly broadened $(\mathrm{FWHM}=1.63 \mathrm{eV})$ and significantly shifted to lower binding energy $(532.30 \mathrm{eV})$. The large FWHM, much greater than that at $300 \mathrm{~K}(1.1 \mathrm{eV})$, suggests it encompasses two or more contributions. The spectrum can be fitted again by substituting the broad main component at $532.30 \mathrm{eV}$ by a doublet consisting in two components of equal intensity, with a FWHM of $1.17 \mathrm{eV}$ each. The resulting fit is shown in Figure S5. The high binding energy component of the doublet is only at $+0.1 \mathrm{eV}$ from that of the "isolated" $\mathrm{OH}$, while the low binding energy one is at $-0.72 \mathrm{eV}$. The QC calculations have shown that the magnitude of $\Delta \mathrm{IE}_{Q C}^{\text {th }}$ is much less for $\mathrm{OH}(\mathrm{A})$ than for $\mathrm{OH}(\mathrm{D})$ in the $\mathrm{OH}(\mathrm{D}) \ldots \mathrm{NH}_{3}(\mathrm{~A}, \mathrm{D}) \ldots \mathrm{OH}(\mathrm{A})$ configuration (see Table $\mathrm{S} 1$ ). To ease the comparison between theory and experiment, the theoretical energy positions of $\mathrm{OH}(\mathrm{A})$ and $\mathrm{OH}(\mathrm{D})$ are indicated by a red and a violet vertical bar, respectively. However, the large $\mathrm{IE}_{Q C}^{\text {th }}$ splitting of $1.5 \mathrm{eV}$ is greater than that obtained from the experimental fit $(0.82 \mathrm{eV})$. This suggests that the H-bonding pattern of $\mathrm{OHs}$ is much more complex than the assumption of singly H-bonded $\mathrm{OH}(\mathrm{A})$ and $\mathrm{OH}(\mathrm{D})$. The green bar in Figure S5 represents the $\mathrm{OH}(\mathrm{a}, \mathrm{D})$ component and the orange one that of a $\mathrm{OH}(\mathrm{d})$ component (see Table S1). To sum up, the global shift of the peak maximum to lower binding energy and its broadening can be explained qualitatively by the QC calculations, assuming a distribution of $\mathrm{OH}(\mathrm{D}), \mathrm{OH}(\mathrm{d}), \mathrm{OH}(\mathrm{a}, \mathrm{D})$ and $\mathrm{OH}(\mathrm{A})$ hydroxyls.

\footnotetext{
${ }^{1}$ One could attribute this peak to an $\mathrm{OH}$ sitting close to a datively bonded ammonia which bears a Lewis charge of +1 .
} 


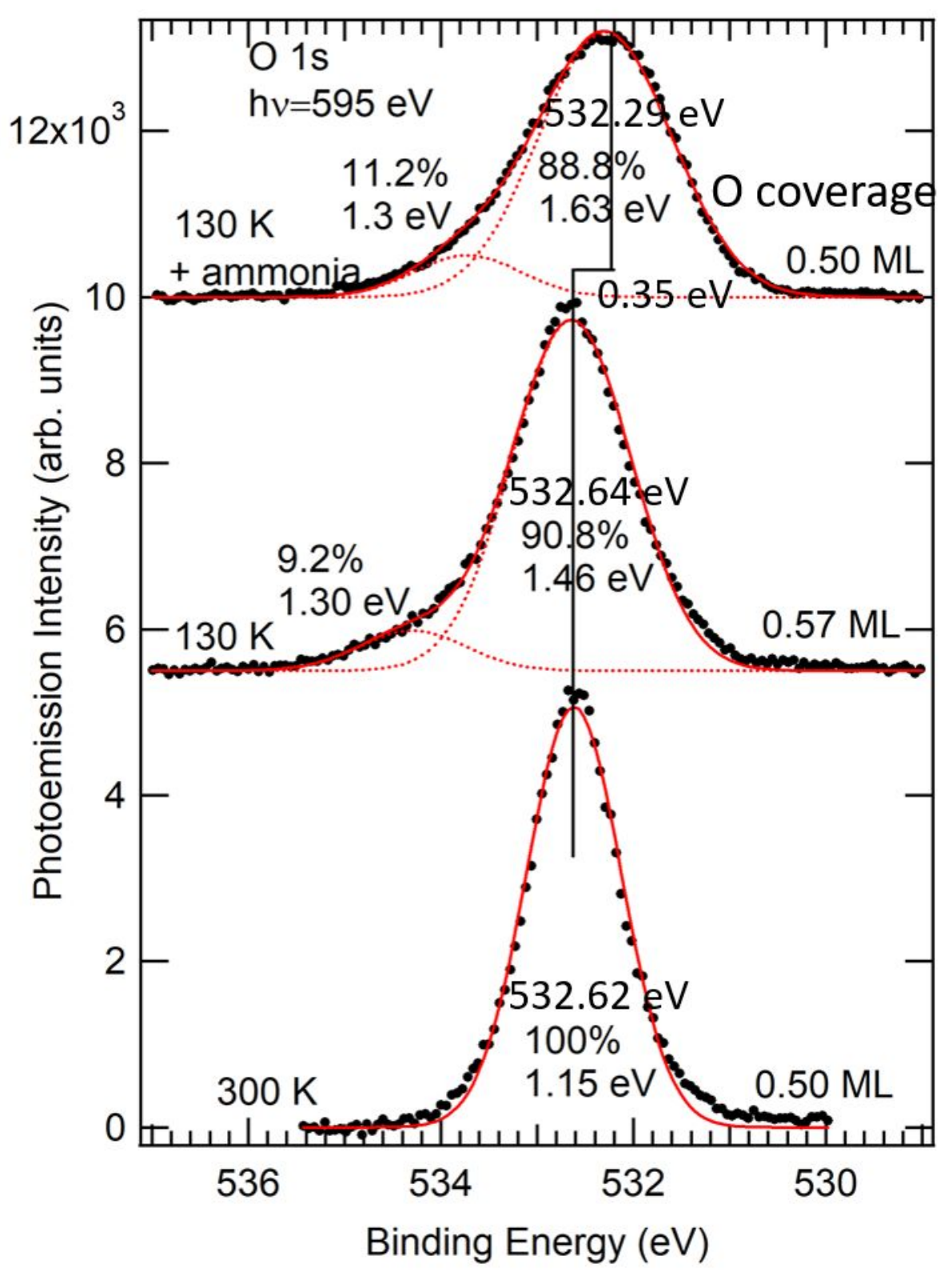

Figure S4. O 1 s spectra measured at $h v=595 \mathrm{eV}$. The spectra are normalized with respect to the $\mathrm{O}$ 1s intensity of the $(\mathrm{H}, \mathrm{OH})-\mathrm{Si}(001)$ surface at $300 \mathrm{~K}$. The oxygen coverage is indicated. Fits (solid red line) are also shown. The spectral weights (\%) and FWHM of the Gaussian components (dotted red lines) are indicated. 


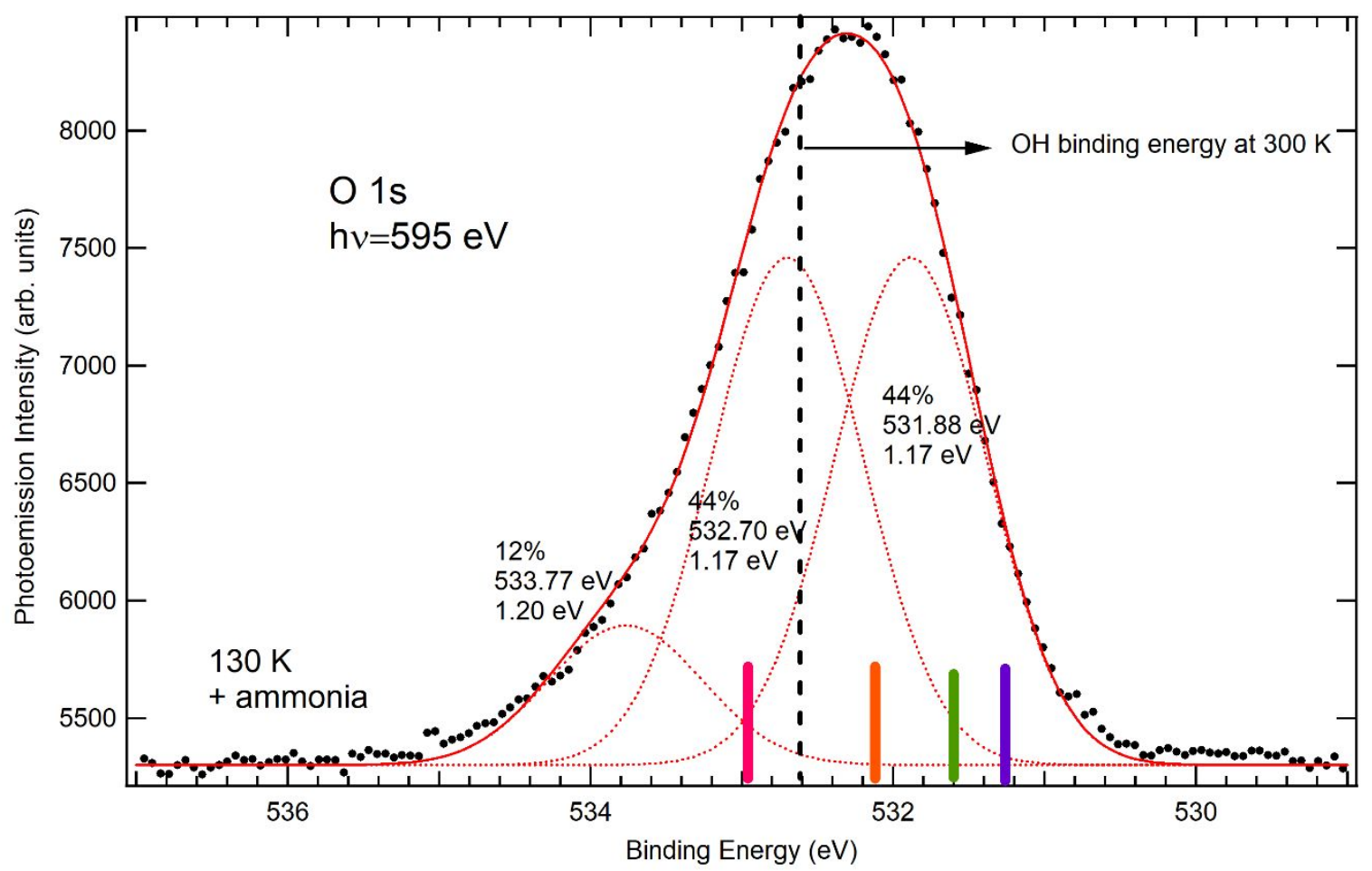

Figure S5. Normalized O 1 s spectra of the $(\mathrm{H}, \mathrm{OH})$-Si(001) surface at $130 \mathrm{~K}$ covered by ammonia. The dashed vertical line corresponds to the binding energy of the OHs at $300 \mathrm{~K}$ (noninteracting OHs). Fits (solid red line) are also shown. The spectral weights (\%), energy positions and FWHM of the Gaussian components (dotted red lines) are indicated. The violet and fuschsia vertical bars indicate the $\Delta I E_{Q C}^{\text {th }}$ of the $O H(D)$ and $O H(A)$ in a $\mathrm{OH}(D) \ldots \mathrm{NH}_{3}(A, d) \ldots \mathrm{OH}(A)$ configuration (the reference is the dashed vertical line). Similarly, the orange and the green bars indicate the $\Delta I E_{Q C}^{t h}$ of the $O H(d)$ and $O H(a, D)$ in a $\mathrm{OH}(d) \ldots \mathrm{OH}(a, D) \ldots \mathrm{NH}_{3}(\mathrm{~A})$ configuration (see Table S1).

\section{S5. Trimethylamine (TMA) adsorption on $(\mathrm{H}, \mathrm{OH})-\mathrm{Si}(001)$ at $130 \mathrm{~K}$}

We show in Figure S6 the N 1s spectrum measured at $h v=455 \mathrm{eV}$ after exposure of $(\mathrm{H}, \mathrm{OH})-$ $\mathrm{Si}(001)$ to trimethylamine (TMA) under a pressure of $5.10^{-9}$ mbar for $140 \mathrm{~s}$. Molecules can make H-bonds with the surface OHs. However, the most interesting observation is that 0.03 ML of molecules can make a dative bonding with the isolated dangling bonds ( 0.04 ML) present on the surface. Thus, this observation is general for Lewis bases. This suggests that these molecules can dope the surface layers. A detailed report on TMA adsorption on (H,OH)$\mathrm{Si}(001)$ at $130 \mathrm{~K}$ is in preparation. 


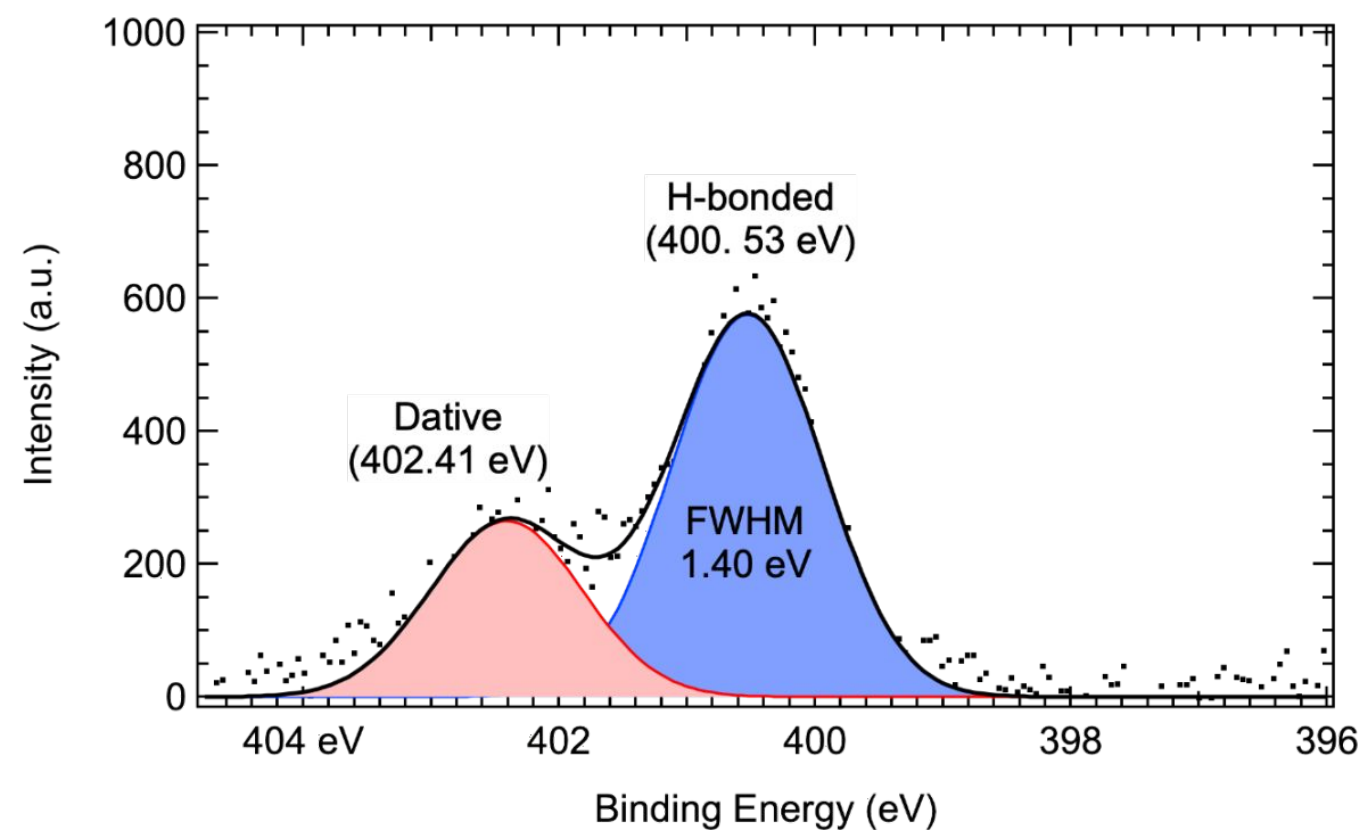

Figure S6: $N$ 1s spectrum of the (H,OH)-Si(001) surface exposed to TMA at $130 \mathrm{~K}$ under a pressure of $5.10^{-9}$ mbar for $140 \mathrm{~s}$. The photon energy is $455 \mathrm{eV}$. The blue component is attributed to TMA molecules making acceptor H-bonds with OHs and corresponds to a coverage of $0.07 \mathrm{ML}$, while the red component, attributed to dative bonding, corresponds to a coverage of $0.03 \mathrm{ML}$.

\section{References}

(1) Tanuma, S.; Powell, C. J.; Penn, D. R. Calculations of Electron Inelastic Mean Free Paths. Surf. Interface Anal. 2005, 37 (1), 1-14. https://doi.org/10.1002/sia.1997.

(2) Gallet, J.-J.; Bournel, F.; Rochet, F.; Köhler, U.; Kubsky, S.; Silly, M.; Sirotti, F.;

Pierucci, D. Isolated Silicon Dangling Bonds on a Water-Saturated $<$ italic $>$ n $</$ Italic $>^{+}-$

Doped Si(001)-2 × 1 Surface: An XPS and STM Study. J. Phys. Chem. C 115 (15), 7686-7693. https://doi.org/10.1021/jp201262x.

(3) Bournel, F.; Gallet, J.-J.; Pierucci, D.; Khaliq, A.; Rochet, F.; Pietzsch, A.

Hydrosilylation of Styrene on Water-Saturated $\mathrm{Si}(001)-2 \times 1$ at Room Temperature. $J$. Phys. Chem. C 2011, 115 (30), 14827-14833. https://doi.org/10.1021/jp202913y.

(4) Gallet, J. J.; Bournel, F.; Rochet, F.; Köhler, U.; Kubsky, S.; Silly, M. G.; Sirotti, F.; 
Pierucci, D. Isolated Silicon Dangling Bonds on a Water-Saturated N+-Doped Si(001)$2 \times 1$ Surface: An XPS and STM Study. J. Phys. Chem. C 2011, 115 (15), 7686-7693. https://doi.org/10.1021/jp201262x.

(5) Mathieu, C.; Bai, X.; Bournel, F.; Gallet, J.-J.; Carniato, S.; Rochet, F.; Sirotti, F.;

Silly, M. G.; Chauvet, C.; Krizmancic, D.; et al. Nitrogen 1s NEXAFS and XPS Spectroscopy of NH3-Saturated Si(001)-2×1: Theoretical Predictions and Experimental Observations at 300 K. Phys. Rev. B 2009, 79 (20), 205317.

https://doi.org/10.1103/PhysRevB.79.205317.

(6) Carniato, S.; Gallet, J.-J.; Rochet, F.; Dufour, G.; Bournel, F.; Rangan, S.; Verdini, A.; Floreano, L. Characterization of Hydroxyl Groups on Water-Reacted Si(001)-2×1 Using Synchrotron Radiation O 1s Core-Level Spectroscopies and Core-Excited State Density-Functional Calculations. Phys. Rev. B 2007, 76 (8), 085321. https://doi.org/10.1103/PhysRevB.76.085321.

(7) Garcia-Gil, S.; Arnau, A.; Garcia-Lekue, A. Exploring Large O 1s and N 1s Core Level Shifts Due to Intermolecular Hydrogen Bond Formation in Organic Molecules. Surf. Sci. 2013, 613, 102-107. https://doi.org/10.1016/j.susc.2013.03.017.

(8) Larsson, C. U. S.; Johnson, A. L.; Flodström, A.; Madey, T. E. Adsorption of H 2 O on Planar and Stepped Si(100): Structural Aspects. J. Vac. Sci. Technol. A Vacuum, Surfaces, Film. 1987, 5 (4), 842-846. https://doi.org/10.1116/1.574322. 